\title{
DISTRIBUIÇÃO LONGITUDINAL DE SEMENTES DE SOJA E CARACTERÍSTICAS FíSICAS DO SOLO NO PLANTIO DIRETO
}

\author{
JORGE W. CORTEZ ${ }^{1}$, CARLOS E. A. FURLANI ${ }^{2}$, ROUVERSON P. DA SILVA ${ }^{3}$, \\ AFONSO LOPES ${ }^{2}$
}

\begin{abstract}
RESUMO: As técnicas do plantio direto são complementares às atuais técnicas de conservação do solo, que envolvem menor mobilização e permanência de cobertura vegetal na superfície do solo. O trabalho foi realizado na UNESP - Jaboticabal, de novembro de 2003 a março de 2004, e teve como objetivo avaliar o efeito de culturas, manejos e marchas do trator na semeadura da soja no plantio direto. $\mathrm{O}$ delineamento utilizado para instalação do experimento foi em blocos ao acaso, no esquema de parcelas subsubdivididas, com quatro repetições. Foram analisados: estande inicial, distribuição longitudinal de plantas, resistência mecânica à penetração, densidade e teor de água no solo. O estande inicial não foi influenciado pelos tratamentos. A distribuição longitudinal das plantas foi afetada pela marcha do trator. A resistência do solo à penetração sofreu efeito apenas na camada de 0,20 a 0,25 m na interação culturas, manejos e marchas do trator. A interação culturas e manejos na camada de 0,10 a $0,20 \mathrm{~m}$ para densidade indicou a presença de resistência maior do que 0 a $0,10 \mathrm{~m}$ e de 0,20 a $0,30 \mathrm{~m}$. O teor de água no solo foi menor nas camadas superficiais do solo, influenciado pelos manejos.
\end{abstract}

PALAVRAS-CHAVE: velocidade, manejo, mecanização agrícola.

\section{LONGITUDINAL SPACING UNIFORMITY OF THE SOYBEAN SEEDS AND PHYSICAL CHARACTERISTICS OF THE SOIL IN NO TILLAGE}

\begin{abstract}
The techniques of the no tillage are complemental to the current techniques of conservation of the soil, which involve smaller mobilization and larger amount of vegetable covering in the surface of the soil. The work was accomplished in UNESP - Jaboticabal, Brazil, of November from 2003 to march of 2004 and had as objective evaluates the effect of cultures, handlings and marches of the set tractor-seeder in the sowing of the soybean in no tillage. The used experimental for installation was randomized block design in split-split-plot, with four replications. It was analyzed: initial stand, seed spacing uniformity, resistance to penetration, bulk density and soil moisture. The initial stand was not influenced by the treatments. The seed spacing uniformity was affected by the march of the tractor-seeder. The resistance to penetration suffered effect just in the layer from 0.20 to $0.25 \mathrm{~m}$ in the interaction cultures, handlings and marches of the tractor. The interaction cultures and handlings in the layer from 0.10 to $0.20 \mathrm{~m}$ for bulk density indicated the presence of compacted layer than 0 to $0.10 \mathrm{~m}$ and 0.20 to $0.30 \mathrm{~m}$. The soil moisture was smaller in the superficial layers of the soil influenced by the handlings.
\end{abstract}

KEYWORDS: speed, handling, agricultural mechanization.

\footnotetext{
${ }^{1}$ Eng ${ }^{o}$ Agrônomo, Pós-Graduando em Agronomia - Produção Vegetal, Departamento de Engenharia Rural, UNESP - Jaboticabal SP, jorge.cortez@posgrad.fcav.unesp.br

2 Prof. Adjunto, Departamento de Engenharia Rural, UNESP - Jaboticabal, Via de Acesso Prof Paulo Donato Castellane, s/n, Jaboticabal - SP, Fone: (0XX16) 3209.2637.

${ }^{3}$ Prof. Dr., Departamento de Engenharia Rural, UNESP - Jaboticabal - SP.

Recebido pelo Conselho Editorial em: 21-12-2005
}

Aprovado pelo Conselho Editorial em: 29-5-2006 


\section{INTRODUÇÃO}

O plantio direto visa a manter no solo uma cobertura vegetal, que é o fator-chave. Cultivo de cobertura pode ser mantido pelo uso de rotação de culturas que proporcionam diferentes tipos de matéria seca com relações diferentes de carbono/nitrogênio $(\mathrm{C} / \mathrm{N})$, pois quanto maior essa relação, maior será o tempo de permanência da camada morta no solo. Apresenta, como vantagem, a redução dos custos operacionais de mecanização, além dos aspectos conservacionistas das características físicas, químicas e biológicas do solo (NAGAOKA \& NOMURA, 2003).

O plantio direto preconiza manter a superfície do solo com a maior quantidade de resíduos possível e no maior tempo, evitando, assim, efeito das intempéries do clima. O manejo da vegetação tem, por finalidade, cortar ou reduzir o comprimento da mesma e fornecer condições adequadas para utilização de máquinas de preparo do solo e semeadoras (FURLANI et al., 2003).

A velocidade na operação de semeadura tem influência direta sobre a cobertura das sementes, independentemente do tipo e marca da semeadora. A maioria das pesquisas aponta velocidades de 5 a $7 \mathrm{~km} \mathrm{~h}^{-1}$ como ideais. Considerando as condições da área e da semeadora em uso, a maior velocidade poderá abrir sulcos maiores, revolvendo uma faixa mais larga e, em consequiência, a roda compactadora não pressionará suficientemente o solo sobre a semente (NAGAOKA \& NOMURA, 2003).

A distribuição longitudinal de sementes é afetada pela velocidade de deslocamento, que, por sua vez, influencia na produtividade da cultura e no desempenho de semeadoras-adubadoras (DELAFOSSE, 1986).

Dentre as limitações que um solo pode impor à planta, a compactação causa restrição ao crescimento e ao desenvolvimento radicular que, por sua vez, afeta direta e indiretamente a produção. Além disso, a compactação está relacionada com os atributos físicos, químicos e biológicos, que são importantes ao desenvolvimento das plantas, como as quantidades de ar, água e temperatura presentes no solo (CAMARGO \& ALLEONI, 1997).

As marchas do trator utilizadas na operação de semeadura proporcionam velocidades que podem ocasionar interferência na distribuição longitudinal de plantas. Os cultivos de cobertura e o seu manejo podem influenciar pelas distintas condições da relação rodado-solo, que, por sua vez, poderá alterar as características físicas do solo como: resistência à penetração, densidade e teor de água.

O objetivo do trabalho foi avaliar o efeito de duas culturas para a produção de palha (milheto e sorgo) em plantio direto, juntamente com três tipos de manejos dessas culturas com rolo-faca, triturador de palhas tratorizado e herbicida, em diferentes marchas do trator, na operação de semeadura de soja, para algumas características físicas do solo, estande inicial e distribuição longitudinal de plantas.

\section{MATERIAL E MÉTODOS}

O experimento foi conduzido na área do Laboratório de Máquinas e Mecanização Agrícola (LAMMA) do Departamento de Engenharia Rural da Faculdade de Ciências Agrárias e Veterinárias da Universidade Estadual Paulista - UNESP, Jaboticabal, São Paulo, localizada nas coordenadas geodésicas: latitude $21^{\circ} 14^{\prime} \mathrm{S}$ e longitude $48^{\circ} 16^{\prime} \mathrm{W}$, com altitude média de $559 \mathrm{~m}$, declividade média de $4 \%$ e clima tipo Cwa (subtropical), de acordo com a classificação de Köeppen.

O solo da área experimental foi classificado por ANDRIOLLI \& CENTURION (1999) como Latossolo Vermelho eutroférrico típico, A moderado, textura argilosa e relevo ondulado, conforme o Sistema Brasileiro de Classificação dos Solos (EMBRAPA, 1999).

O delineamento experimental utilizado foi em parcelas subsubdivididas com a casualização dos tratamentos em blocos ao acaso, com três fatores $(2 \times 3 \times 3)$ e quatro repetições. O fator cultura 
para palhada (milheto e sorgo), o manejo com os equipamentos rolo-faca, triturador de palhas tratorizado e pulverizador para aplicação de herbicida, e as três marchas $\left(\mathrm{Mr} 1=4,24 \mathrm{~km} \mathrm{~h}^{-1}, \mathrm{Mr} 2=\right.$ 4,88 $\mathrm{km} \mathrm{h}^{-1}$ e $\mathrm{Mr} 3=6,00 \mathrm{~km} \mathrm{~h}^{-1}$ ) foram conduzidos, respectivamente, na parcela, subparcela e subsubparcela (20 $\mathrm{m}$ de comprimento por 4,05 $\mathrm{m}$ de largura).

Foi utilizado um trator Valtra BM-100, 4 x 2 (TDA), com 73,6 kW de potência no motor $(100 \mathrm{cv})$, para a operação de semeadura na cultura da soja. Utilizou-se semeadora-adubadora de precisão pneumática da marca Marchesan (TATU), modelo COP Suprema, com sete linhas de semeadura, dotada de disco de corte para palhada, cinzel para sulcamento (adubo) e disco duplo desencontrado para deposição da semente. Para o manejo, utilizaram-se o triturador de coberturas vegetais tratorizado marca Jan, modelo Tritton 2300 montado, com rotor horizontal de 0,60 m, largura de corte de 2,3 m, 32 pares de facas curvas oscilantes e reversíveis, de regulagem de altura de corte e massa de $735 \mathrm{~kg}$; o rolo-faca simples com 13 facas dispostas em sua periferia, largura de corte de $2,10 \mathrm{~m}$ e massa com lastro de $720 \mathrm{~kg}$, e pulverizador marca Jacto, modelo PJ 600, montado, com tanque para capacidade de $600 \mathrm{~L}$ de calda, com massa de $195 \mathrm{~kg}$, barra de $9 \mathrm{~m}$, equipada com 18 bicos tipo leque $\left(110^{\circ}\right)$ para aplicação de herbicidas e bicos cônicos para aplicação de defensivos na soja.

Na determinação do estande inicial, utilizou-se um sarrafo de madeira de $1 \mathrm{~m}$, com cabo no centro, formando um " $\mathrm{T}$ " invertido, que foi o referencial para a contagem das plantas na parte central da subsubparcela.

A percentagem de espaçamentos aceitáveis, falhos e duplos foi obtida de acordo com as normas da ABNT (1984) e KURACHI et al. (1989). As uniformidades foram simuladas, considerando-se percentagens de espaçamentos: "duplos" (D), menores que 0,5 vez o espaçamento médio esperado (Xref.); "aceitáveis" (A), de 0,5 a 1,5 vez o espaçamento médio esperado (Xref.), e "falhos" (F) maiores que 1,5 vez o espaçamento médio esperado (Xref.). O nível de uniformidade mencionado foi relativo às percentagens de espaçamentos aceitáveis, considerando como aceitáveis os espaçamentos situados entre 0,5 a $1,5 \mathrm{vez}$ o espaçamento médio esperado de $0,0553 \mathrm{~m}$ para Mr1; 0,0518 m para Mr2, e 0,0530 m para Mr3.

Para a determinação da resistência do solo à penetração, utilizou-se um penetrômetro de impacto modelo IAA/Planalsucar, desenvolvido por STOLF et al. (1983), que forneceu os dados em impactos $\left(\mathrm{dm}^{-1}\right)$.

As amostras indeformadas para a avaliação de densidade foram coletadas por amostrador com anéis volumétricos $\left(86,808 \mathrm{~cm}^{3}\right)$ com bordas cortantes, nas camadas de 0-0,10; 0,10-0,20 e 0,20-0,30 m. Após a coleta das amostras, foram colocadas em estufa na temperatura de $105-110{ }^{\circ} \mathrm{C}$ até massa constante, segundo metodologia da EMBRAPA (1997). Depois de secas, foram pesadas para a obtenção dos valores para o cálculo da densidade, empregando-se a eq.(1). As observações tomadas foram apenas nos fatores culturas e manejos, analisadas em parcela subdividida.

$$
\text { Ds }=\frac{M}{V}
$$

em que,

$$
\begin{aligned}
& \text { Ds - densidade, } \mathrm{kg} \mathrm{dm}^{-3} \text {; } \\
& \mathrm{M} \text { - massa do solo, } \mathrm{kg}, \mathrm{e} \\
& \text { V - volume total, } \mathrm{dm}^{3} \text {. }
\end{aligned}
$$

O teor de água no solo foi expresso em percentagem, e as observações tomadas foram apenas nos fatores culturas e manejos, analisadas em parcela subdividida. Utilizaram-se os mesmos anéis da densidade para a determinação do teor de água no solo. As amostras foram mensuradas após terem sido coletadas no campo e levadas à estufa a $105-110^{\circ} \mathrm{C}$, durante 24 horas, para a determinação da massa seca. Procedeu-se o calculo do teor médio de água no solo pela eq.(2). 


$$
\mathrm{TMA}=\frac{(\mathrm{MI}-\mathrm{MII})}{(\mathrm{MII}-\mathrm{TA})} 100
$$

em que,

TMA - teor médio de água contido no solo, \%;

MI - massa úmida de solo mais o peso do anel, g;

MII - massa seca de terra mais o peso do anel, g, e

TA - peso do anel, g.

\section{RESULTADOS E DISCUSSÃO}

Os valores do estande inicial, apresentados na Tabela 1 , mostram que não foi afetado pelas diferentes culturas, manejos e marchas do trator na operação de semeadura. A média geral de ensaio foi de 17,44 plantas por metro linear. Observou-se que mesmo alterando as condições de semeadura, a distribuição de sementes foi uniforme, como preestabelecido na regulagem. Segundo BRANQUINHO (2003), em experimento com diferentes manejos e marchas do trator na operação de semeadura, o número médio de plantas não foi afetado pelos tratamentos, cuja média foi de 23.

TABELA 1. Síntese da análise de variância e do teste de médias para número de plantas por metro (estande) e espaçamentos entre plantas (\%).

\begin{tabular}{|c|c|c|c|c|}
\hline \multirow{2}{*}{ Fatores } & \multicolumn{3}{|c|}{ Variáveis } & \multirow[b]{2}{*}{ Duplos } \\
\hline & Estande & Aceitáveis & Falhos & \\
\hline \multicolumn{5}{|l|}{ Culturas (C) } \\
\hline Milheto & 17,19 & 59,31 & 23,66 & 17,77 \\
\hline Sorgo & 17,69 & 59,20 & 21,54 & 19,43 \\
\hline \multicolumn{5}{|l|}{ Manejo (M) } \\
\hline Rolo-faca & 17,25 & 60,29 & 24,37 & 17,44 \\
\hline Triturador & 17,41 & 57,38 & 22,25 & 18,52 \\
\hline Herbicida & 17,66 & 60,09 & 21,17 & 19,84 \\
\hline \multicolumn{5}{|l|}{ Marchas (Mr) } \\
\hline $\mathrm{Mr} 1$ & 16,80 & $65,53 \mathrm{a}$ & $18,61 \mathrm{~b}$ & $16,37 \mathrm{a}$ \\
\hline $\mathrm{Mr} 2$ & 18,33 & $61,53 \mathrm{a}$ & $21,88 \mathrm{ab}$ & $16,36 \mathrm{a}$ \\
\hline $\mathrm{Mr} 3$ & 17,16 & $50,69 \mathrm{~b}$ & $27,31 \mathrm{a}$ & $23,07 \mathrm{a}$ \\
\hline \multicolumn{5}{|l|}{ Teste F } \\
\hline Culturas (C) & $0,71^{\mathrm{NS}}$ & $0,02^{\mathrm{NS}}$ & $0,82^{\mathrm{NS}}$ & $0,26^{\mathrm{NS}}$ \\
\hline Manejos (M) & $0,14^{\mathrm{NS}}$ & $0,25^{\mathrm{NS}}$ & $0,59^{\mathrm{NS}}$ & $0,35^{\mathrm{NS}}$ \\
\hline Marchas (Mr) & $2,78^{\mathrm{NS}}$ & $7,55 * *$ & $4,76 * *$ & $3,77 *$ \\
\hline $\mathrm{C} \times \mathrm{M}$ & $0,71^{\mathrm{NS}}$ & $0,68^{\mathrm{NS}}$ & $2,18^{\mathrm{NS}}$ & $0,52^{\mathrm{NS}}$ \\
\hline $\mathrm{C} \times \mathrm{Mr}$ & $1,21^{\mathrm{NS}}$ & $0,51^{\mathrm{NS}}$ & $0,47^{\mathrm{NS}}$ & $0,98^{\mathrm{NS}}$ \\
\hline $\mathrm{M}$ x Mr & $1,74^{\mathrm{NS}}$ & $0,27^{\mathrm{NS}}$ & $0,94^{\mathrm{NS}}$ & $0,72^{\mathrm{NS}}$ \\
\hline $\mathrm{C} \times \mathrm{M} \times \mathrm{Mr}$ & $1,22^{\mathrm{NS}}$ & $0,54^{\mathrm{NS}}$ & $0,53^{\mathrm{NS}}$ & $0,76^{\mathrm{NS}}$ \\
\hline \multicolumn{5}{|l|}{ C.V.(\%) } \\
\hline Culturas & 14,04 & 15,18 & 43,73 & 74,29 \\
\hline Manejos & 18,19 & 26,67 & 45,52 & 52,94 \\
\hline Marchas & 13,25 & 23,09 & 43,61 & 52,41 \\
\hline Média Geral & 17,44 & 59,25 & 22,60 & 18,60 \\
\hline
\end{tabular}

Em cada coluna, para cada fator, médias seguidas de mesmas letras minúsculas não diferem entre si, pelo teste de Tukey, a $5 \%$ de probabilidade. ${ }^{\mathrm{NS}}$ : não-significativo $(\mathrm{P} \geq 0,05)$; *: significativo $(\mathrm{P} \leq 0,05)$; **: significativo $(\mathrm{P} \leq 0,01)$, C.V.: coeficiente de variação.

A distribuição longitudinal das plantas foi influenciada pelo fator marcha do trator, cuja média geral para os espaçamentos foi 59,25\% para os aceitáveis, 22,60\% para os falhos e 18,60\% para os duplos (Tabela 1). Quanto maior foi a marcha (maior velocidade), menor a quantidade de espaçamentos aceitáveis e maior a quantidade de espaçamentos falhos. $\mathrm{O}$ espaçamento duplo, pelo 
teste F, foi significativo, mas ao ser analisado pelo teste de Tukey, não ocorreram médias diferentes entre si, explicado pelos testes possuírem diferentes poderes para detectar diferenças entre médias.

De acordo com BRANQUINHO (2003), a distribuição longitudinal de plantas não diferiu entre os tratamentos, e o espaçamento aceitável foi de $45 \%$, o falho de $23 \%$ e o duplo de $32 \%$. KLEIN et al. (2002), estudando os efeitos da velocidade de semeadura da soja, apresentaram resultados de $24 \%, 38 \%$ e $38 \%$ para espaçamentos falhos, duplos e aceitáveis, respectivamente, e afirmam que o aumento de velocidade não afetou o percentual pesquisado.

De acordo com COPETTI (2003), o percentual de espaçamentos falhos passou de $7,1 \%$ para $24,9 \%$, duplos de $8,2 \%$ para $14,1 \%$ e aceitáveis de $84,7 \%$ para $61 \%$ quando a velocidade foi de $4,5 \mathrm{~km} \mathrm{~h}^{-1}$ para $8,0 \mathrm{~km} \mathrm{~h}^{-1}$.

O teste de Tukey, a $5 \%$ de probabilidade, mostrou que, na camada de 0,0-0,10 m, o manejo das culturas com o triturador de palhas tratorizado e o herbicida obtiveram as maiores médias. $\mathrm{O}$ rolo-faca obteve a menor média; isso pode ser devido à ação dos órgãos ativos tocarem o solo fazendo com que esse, ficando exposto, diminuísse o teor de água, enquanto o manejo com triturador de palhas tratorizado e herbicida não promoveram a mobilização do solo, permanecendo a cobertura. Na camada de 0,10-0,20 m, a interação culturas e manejos foi significativa (Tabela 2), e a camada de 0,20-0,30 $\mathrm{m}$ de profundidade não foi afetada para os tratamentos analisados. Os resultados indicaram que não ocorreu influência dos tratamentos no teor médio de água em maiores profundidades, apenas superficialmente.

TABELA 2. Síntese de análise de variância e do teste de médias para os valores médios de teor de água no solo (\%), nas diferentes camadas, durante o estádio de desenvolvimento da cultura de soja (R4), no momento da determinação da resistência do solo à penetração.

\begin{tabular}{|c|c|c|c|}
\hline \multirow{2}{*}{ Fatores } & \multicolumn{3}{|c|}{ Camada (m) } \\
\hline & 0 a 0,10 & 0,10 a 0,20 & 0,20 a 0,30 \\
\hline \multicolumn{4}{|l|}{ Culturas (C) } \\
\hline Milheto & 24,56 & 22,22 & 23,09 \\
\hline Sorgo & 24,22 & 22,05 & 22,63 \\
\hline \multicolumn{4}{|l|}{ Manejos (M) } \\
\hline Rolo-faca & $22,71 \mathrm{~b}$ & $22,49 \mathrm{a}$ & 23,71 \\
\hline Triturador & $25,25 \mathrm{a}$ & $22,45 \mathrm{a}$ & 22,55 \\
\hline Herbicida & $25,20 \mathrm{a}$ & $21,46 \mathrm{~b}$ & 22,33 \\
\hline \multicolumn{4}{|l|}{ Teste de F } \\
\hline Culturas (C) & $0,26^{\mathrm{NS}}$ & $0,24^{\mathrm{NS}}$ & $0,25^{\mathrm{NS}}$ \\
\hline Manejos (M) & $6,44 *$ & $3,67 *$ & $0,85^{\mathrm{NS}}$ \\
\hline $\mathrm{C} \times \mathrm{M}$ & $0,40^{\mathrm{NS}}$ & $5,95 *$ & $0,23^{\mathrm{NS}}$ \\
\hline C. V. (\%) & 6,60 & 3,88 & 9,90 \\
\hline Média Geral & 24,39 & 22,13 & 22,86 \\
\hline
\end{tabular}

Em cada coluna, para cada fator, médias seguidas de mesmas letras minúsculas não diferem entre si pelo teste de Tukey, a $5 \%$ de probabilidade. ${ }^{\text {NS }}$ : não-significativo $(\mathrm{P} \geq 0,05)$; *: significativo $(\mathrm{P} \leq 0,05)$; **: significativo $(\mathrm{P} \leq 0,01)$, C.V.: coeficiente de variação.

TABELA 3. Desdobramento de médias para a interação culturas x manejos para o teor de água no solo (\%), na camada de 0,10 a $0,20 \mathrm{~m}$.

\begin{tabular}{ccc}
\hline \multirow{2}{*}{ Manejo } & \multicolumn{2}{c}{ Culturas } \\
\cline { 2 - 3 } & Milheto & Sorgo \\
\hline Rolo-faca & $20,76 \mathrm{~b} \mathrm{~A}$ & 22,17 a B \\
Triturador & 22,65 a A & 22,25 a A \\
Herbicida & 23,26 a A & 21,22 a B \\
\hline
\end{tabular}

Em cada coluna, para cada fator, médias seguidas de mesma letra maiúscula e, em cada linha, para cada fator, médias seguidas de letra minúscula não diferem entre si, pelo teste de Tukey, a 5\% de probabilidade. 
Na camada de 0,10-0,20 m, o sorgo apresentou o maior teor de água no solo no manejo com rolo-faca, e os demais não diferiram entre si (Tabela 3). Na cultura do milheto, os manejos não foram influenciados. Analisando os manejos, o triturador de palhas tratorizado resultou em maiores valores na cultura do sorgo, enquanto o rolo-faca e o herbicida não diferiram. O triturador de palhas tratorizado proporcionou a melhor cobertura do solo, o que, provavelmente, causou o maior teor de água no solo para esse tratamento.

Segundo BRANQUINHO (2003), o teor de água no solo não provocou diferença em nenhuma das camadas estudadas, sendo o valor médio de $25,7 \%$ na camada de $0-0,10 \mathrm{~m}$ e na de 0,10-0,20 m, e de 0,20-0,30 m obteve 26,1\%. De acordo com BARBER et al. (1996), o teor de água no solo, conduzido em plantio convencional e plantio direto, é de $24,9 \%$ e $24,9 \%$, na camada de $0-0,20 \mathrm{~m}$, e de 21,3 e $23,4 \%$, na camada de 0,20-0,40 m, respectivamente, indicando pouca diferença entre os tipos de preparo. Ao contrário, MIELKE et al. (1986) observaram que o experimento realizado em plantio direto apresentou de $2 \%$ a $11 \%$ a mais de água do que o conduzido em plantio convencional.

Na Tabela 4, são apresentados os resultados da análise estatística da resistência à penetração. Apenas para a camada de 0,20-0,25 m houve a interação C x M x Mr significativa pelo teste F.

TABELA 4. Síntese de análise de variância e do teste de médias para resistência do solo à penetração.

\begin{tabular}{|c|c|c|c|c|c|c|c|c|c|c|}
\hline \multirow{2}{*}{ Fatores } & \multicolumn{10}{|c|}{ Camadas (m) } \\
\hline & $0,0-0,05$ & $0,5-0,1$ & $0,1-0,15$ & $0,15-0,2$ & $0,2-0,25$ & $0,25-0,3$ & $0,3-0,35$ & $0,35-0,4$ & $0,4-0,45$ & $0,45-0,5$ \\
\hline \multicolumn{11}{|c|}{ Culturas (C) } \\
\hline Milheto & 0,36 & 0,77 & 1,08 & 1,44 & 1,58 & 1,61 & 1,69 & 1,61 & 1,47 & 1,72 \\
\hline Sorgo & 0,66 & 0,86 & 1,19 & 1,47 & 1,62 & 1,63 & 1,69 & 1,86 & 1,80 & 2,02 \\
\hline \multicolumn{11}{|c|}{ Manejo (M) } \\
\hline Rolo-faca & 0,54 & 0,75 & 1,16 & 1,45 & 1,62 & 1,70 & 1,62 & 1,79 & 1,58 & 1,95 \\
\hline Triturador & 0,50 & 0,95 & 1,16 & 1,54 & 1,58 & 1,62 & 1,80 & 1,66 & 1,58 & 1,79 \\
\hline Herbicida & 0,50 & 0,75 & 1,08 & 1,37 & 1,50 & 1,54 & 1,62 & 1,75 & 1,75 & 1,87 \\
\hline \multicolumn{11}{|c|}{ Marchas (Mr) } \\
\hline Mr1 & 0,58 & 0,95 & 1,20 & 1,50 & 1,54 & 1,50 & 1,79 & 1,70 & 1,50 & 1,95 \\
\hline $\mathrm{Mr} 2$ & 0,50 & 0,79 & 1,16 & 1,45 & 1,58 & 1,70 & 1,70 & 1,70 & 1,54 & 1,75 \\
\hline Mr3 & 0,45 & 0,70 & 1,04 & 1,41 & 1,58 & 1,60 & 1,58 & 1,79 & 1,75 & 1,91 \\
\hline \multicolumn{11}{|l|}{ Teste F } \\
\hline$\overline{\mathrm{C}}$ & $0,4^{\mathrm{NS}}$ & $0,1^{\mathrm{NS}}$ & $0,4^{\mathrm{NS}}$ & $0,1^{\mathrm{NS}}$ & $0,3^{\mathrm{NS}}$ & $0,1^{\mathrm{NS}}$ & $0,0^{\mathrm{NS}}$ & $1,2^{\mathrm{NS}}$ & $2,8^{\mathrm{NS}}$ & $2,1^{N S}$ \\
\hline M & $0,6^{\mathrm{NS}}$ & $1,1^{\mathrm{NS}}$ & $0,2^{\mathrm{NS}}$ & $0,3^{\mathrm{NS}}$ & $0,1^{\mathrm{NS}}$ & $0,1^{\mathrm{NS}}$ & $0,5^{\mathrm{NS}}$ & $0,8^{\mathrm{NS}}$ & $0,2^{\mathrm{NS}}$ & $0,1^{\mathrm{NS}}$ \\
\hline $\mathrm{Mr}$ & $0,3^{\mathrm{NS}}$ & $1,2^{\mathrm{NS}}$ & $0,5^{\mathrm{NS}}$ & $0,1^{\mathrm{NS}}$ & $0,1^{\mathrm{NS}}$ & $0,6^{\mathrm{NS}}$ & $0,9^{\mathrm{NS}}$ & $0,1^{\mathrm{NS}}$ & $2,1^{\mathrm{NS}}$ & $0,2^{\mathrm{NS}}$ \\
\hline $\mathrm{C} \times \mathrm{M}$ & $0,8^{\mathrm{NS}}$ & $1,7^{\mathrm{NS}}$ & $3,8^{\mathrm{NS}}$ & $1,9^{\mathrm{NS}}$ & $0,3^{\mathrm{NS}}$ & $0,2^{\mathrm{NS}}$ & $1,3^{\mathrm{NS}}$ & $0,4^{\mathrm{NS}}$ & $1,0^{\mathrm{NS}}$ & $2,2^{\mathrm{NS}}$ \\
\hline $\mathrm{C} \times \mathrm{Mr}$ & $0,1^{\mathrm{NS}}$ & $1,6^{\mathrm{NS}}$ & $0,2^{\mathrm{NS}}$ & $0,3^{\mathrm{NS}}$ & $1,3^{\mathrm{NS}}$ & $0,5^{\mathrm{NS}}$ & $0,4^{\mathrm{NS}}$ & $2,7^{\mathrm{NS}}$ & $1,8^{\mathrm{NS}}$ & $1,8^{\mathrm{NS}}$ \\
\hline $\mathrm{M} \times \mathrm{Mr}$ & $0,6^{\mathrm{NS}}$ & $0,4^{\mathrm{NS}}$ & $0,2^{\mathrm{NS}}$ & $2,3^{\mathrm{NS}}$ & $1,4^{\mathrm{NS}}$ & $0,7^{\mathrm{NS}}$ & $2,2^{\mathrm{NS}}$ & $0,3^{\mathrm{NS}}$ & $0,3^{\mathrm{NS}}$ & $0,5^{\mathrm{NS}}$ \\
\hline CxMxMr & $0,4^{\mathrm{NS}}$ & $0,5^{\mathrm{NS}}$ & $0,8^{\mathrm{NS}}$ & $1,7^{\mathrm{NS}}$ & $2,89 *$ & $1,3^{\mathrm{NS}}$ & $0,8^{\mathrm{NS}}$ & $0,1^{\mathrm{NS}}$ & $1,5^{\mathrm{NS}}$ & $0,5^{\mathrm{NS}}$ \\
\hline M.G. & 0,51 & 0,82 & 1,13 & 1,45 & 1,57 & 1,61 & 1,69 & 1,73 & 1,62 & 1,87 \\
\hline
\end{tabular}

Em cada coluna, para cada fator, médias seguidas de mesmas letras minúsculas não diferem entre si, pelo teste de Tukey, a $5 \%$ de probabilidade. ${ }^{\text {NS }}$ : não-significativo $(\mathrm{P} \geq 0,05)$; *: significativo $(\mathrm{P} \leq 0,05)$; **: significativo $(\mathrm{P} \leq 0,01)$, C.V.: coeficiente de variação. M.G.: Média Geral.

A camada de 0,20-0,25 m sofreu efeito do trânsito de máquinas na área, devido a sucessivos anos de cultivo sem mobilização total do solo, ocorrendo apenas mobilização na linha de semeadura. A Mr3 ocasionou maior resistência à penetração devido ao maior esforço do rodado no solo, ocorrido na maior velocidade desse tratamento, pelo efeito de quebra da estrutura superior e formação de camada compactada abaixo.

No desdobramento da interação tripla ( $\mathrm{C} \times \mathrm{M} \times \mathrm{Mr}$ ), ocorreu efeito na interação marcha dentro de milheto e rolo-faca (Tabela 5). O rolo-faca, por proporcionar o acamamento da cultura, faz pressão sobre o solo e esse, provavelmente, é o motivo da maior resistência à penetração nesse tratamento. 
TABELA 5. Desdobramento da interação tripla (C x M x Mr) da marcha dentro de culturas e manejos na camada de 0,20 a 0,25 m para resistência à penetração.

\begin{tabular}{ccccc}
\hline Tratamentos & Fatores & Médias & $5 \%$ & $1 \%$ \\
\hline \multirow{2}{*}{ Marcha dentro de } & Mr1 & 1,25 & $\mathrm{~b}$ & $\mathrm{~A}$ \\
milheto e rolo-faca & $\mathrm{Mr} 2$ & 1,50 & $\mathrm{ab}$ & $\mathrm{A}$ \\
& $\mathrm{Mr} 3$ & 2,25 & $\mathrm{a}$ & $\mathrm{A}$ \\
\hline
\end{tabular}

HERMAWAN \& CAMERON (1993) observaram que a resistência à penetração foi semelhante entre plantio convencional e cultivo mínimo. No convencional, devido ao excesso de operações com o arado, ocorreu alta resistência à penetração na camada de 0,20-0,35 m. Observase pela literatura, que preparos periódicos do solo podem formar camada compactada mais profunda, necessitando da mobilização total da área para correção. Já em preparos mínimos ou plantio direto, a menor mobilização evita o efeito da compactação profunda, por não usar implementos de preparo do solo, e quando há compactação superficial, essa é eliminada pela haste escarificadora da semeadora-adubadora.

CLARK (1993) cita que, quanto mais tempo o solo permanece em plantio direto, ocorre diminuição da resistência à penetração. No primeiro ano, obteve diferença até $0,21 \mathrm{~m}$, com dois anos até $0,16 \mathrm{~m}$, e com três anos até $0,13 \mathrm{~m}$. À medida que o solo permaneceu em plantio direto, a compactação se tornou superficial, restringindo apenas a pequena camada a $0,13 \mathrm{~m}$, que é destruída pelo uso de haste escarificadora da semeadora-adubadora.

Segundo KLEIN et al. (1998), a resistência à penetração foi altamente influenciada pelo teor de água e a sua determinação, apenas quando o solo se encontra próximo da capacidade de campo, não é recomendável, pois grandes variações de compactação poderão não ser detectadas.

Os valores médios de densidade são apresentados na Tabela 6. Observa-se que não ocorreu diferença para as camadas de 0-0,10 m e 0,20-0,30 m. Na camada de 0,10-0,20 m, obteve-se efeito significativo da interação culturas e manejos. O desdobramento da interação mostrou que não houve diferença pelo teste de Tukey, o que é explicado pelos diferentes poderes dos testes e pela probabilidade de $95 \%$ para ocorrer diferença entre os tratamentos, e de 5\% de não ocorrer (Tabela 7).

TABELA 6. Síntese de análise de variância e do teste de médias para densidade do solo $\left(\mathrm{kg} \mathrm{dm}^{-3}\right)$.

\begin{tabular}{cccc}
\hline \multirow{2}{*}{ Fatores } & \multicolumn{3}{c}{ Camada $(\mathrm{m})$} \\
\cline { 2 - 4 } & 0 a 0,10 & 0,10 a 0,20 & 0,20 a 0,30 \\
\hline Cultura (C) & 1,47 & 1,54 & 1,53 \\
\hline Milheto & 1,43 & 1,53 & 1,53 \\
\hline Sorgo & & 1,56 & 1,52 \\
\hline Manejo (M) & 1,48 & 1,53 & 1,53 \\
\hline Rolo & 1,44 & 1,52 & 1,54 \\
Triturador & 1,43 & $0,13^{\mathrm{NS}}$ & $0,83^{\mathrm{NS}}$ \\
Herbicida & & $1,40^{\mathrm{NS}}$ & $0,20^{\mathrm{NS}}$ \\
\hline Teste F & $2,98^{\mathrm{NS}}$ & $0,22^{\mathrm{NS}}$ \\
\hline Culturas (C) & $2,60^{\mathrm{NS}}$ & $4,14^{*}$ & 3,69 \\
Manejos (M) & $0,65^{\mathrm{NS}}$ & 2,55 & 1,53 \\
C X M & 3,08 & 1,54 &
\end{tabular}

Em cada coluna, para cada fator, médias seguidas de mesmas letras minúsculas não diferem entre si, pelo teste de Tukey, a $5 \%$ de probabilidade. ${ }^{\text {NS}}$ : não-significativo $(\mathrm{P} \geq 0,05)$; *: significativo $(\mathrm{P} \leq 0,05)$; **: significativo $(\mathrm{P} \leq 0,01)$; C.V.: coeficiente de variação. 
TABELA 7. Desdobramento de médias para a interação culturas x manejos para a densidade do solo $\left(\mathrm{kg} \mathrm{dm}^{-3}\right)$, na camada de 0,10 a $0,20 \mathrm{~m}$.

\begin{tabular}{ccc}
\hline \multirow{2}{*}{ Manejos } & \multicolumn{2}{c}{ Culturas } \\
\cline { 2 - 3 } & Milheto & Sorgo \\
Rolo-Faca & 1,56 a A & 1,50 a A \\
Triturador & 1,57 a A & 1,55 a A \\
Herbicida & 1,51 a A & 1,56 a A \\
\hline
\end{tabular}

Em cada coluna, para cada fator, médias seguidas de mesmas letras maiúsculas e, em cada linha, para cada fator, médias seguidas de letras minúsculas não diferem entre si, pelo teste de Tukey, a 5\% de probabilidade.

FURLANI (2000) concluiu que os manejos com triturador, rolo-faca e herbicida não afetaram a densidade do solo nas camadas de 0-0,10 m e 0,10-0,20 m, nas culturas de inverno, o que concorda com este experimento. Segundo SILVEIRA et al. (1999), na camada de 0-0,10 m, o maior valor de densidade $\left(1,24 \mathrm{~kg} \mathrm{dm}^{-3}\right)$ ocorreu com grade aradora e, no plantio direto $\left(1,38 \mathrm{~kg} \mathrm{dm}^{-3}\right)$, devido à não-mobilização do solo e à compactação provocada pelo tráfico de máquinas.

FRANCIS \& KNIGHT (1993), analisando o preparo convencional (PC) e o plantio direto (SPD), observaram que, na camada de $0-0,05 \mathrm{~m}$, a densidade do solo não foi afetada por ambos (1,06 $\left.\mathrm{kg} \mathrm{dm}^{-3}\right)$, na de $0,10-0,15 \mathrm{~m}$, o SPD apresentou $1,16 \mathrm{~kg} \mathrm{dm}^{-3}$ e o PC $1,2 \mathrm{~kg} \mathrm{dm}^{-3}$, e na de 0,20 $0,25 \mathrm{~m}$, ambos resultaram na mesma densidade $\left(1,19 \mathrm{~kg} \mathrm{dm}^{-3}\right)$.

\section{CONCLUSÕES}

Nas culturas de milheto e sorgo, os manejos com rolo-faca, triturador de palhas tratorizados e herbicida na operação de semeadura de soja $\left(4,24 \mathrm{~km} \mathrm{~h}^{-1}\right.$ a $\left.6 \mathrm{~km} \mathrm{~h}^{-1}\right)$ não influenciaram no estande, no sistema de plantio direto.

Maior velocidade na operação de semeadura diminui a quantidade de espaçamentos aceitáveis e aumenta a quantidade de espaçamentos falhos.

$\mathrm{O}$ trânsito de máquinas na área resultou em maior resistência à penetração na camada de 0,20-0,25 m. A interação manejos x culturas foi significativa para a densidade do solo na camada de $0,10-0,20 \mathrm{~m}$.

\section{REFERÊNCIAS}

ANDRIOLI, I.; CENTURION, J.F. Levantamento detalhado dos solos da Faculdade de Ciências Agrárias e Veterinárias de Jaboticabal. In: CONGRESSO BRASILEIRO DE CIÊNCIA DO SOLO, 27., 1999, Brasília. Anais... Brasília: Sociedade Brasileira de Ciência do Solo, 1999. 1 CD-ROM.

ASSOCIAÇÃO BRASILEIRA DE NORMAS TÉCNICAS. Projeto de norma 04:015.06-004 semeadoras de precisão: ensaio de laboratório - método de ensaio. São Paulo, 1984. 26 p.

BARBER, R.G.; ORELLANA, M.; NAVARRO, F.; DIAZ, O.; SORUCO, M.A. Effects of conservation and conventional tillage systems after land clearing on soil properties and crop yield in Santa Cruz, Bolivia. Soil \& Tillage Research, Amsterdam, v.38, n.1, p.133-52, 1996.

BRANQUINHO, K.B. Semeadura direta da soja (Glycine max L.) em função da velocidade de deslocamento e do tipo de manejo do milheto (Pennisetum glaucum $(L) R$. Brow). 2003. $62 \mathrm{f}$. Dissertação (Mestrado em Ciência do Solo) - Faculdade de Ciências Agrárias e Veterinárias, Universidade Estadual Paulista, Jaboticabal, 2003.

CAMARGO, O.A.; ALLEONI, L.R.F. Compactação do solo e o desenvolvimento das plantas. Piracicaba: USP, 1997. 132 p.

CLARK, K.L. Soil strength and water infiltration as affected by paratillage frequency. Trasactions of the ASAE, St. Joseph, v.36, p.130-5, 1993. 
COPETTI, E. Plantadoras: distribuição de sementes. Cultivar Máquinas, Pelotas, n.18, p.14-17, 2003.

DELAFOSSE, R.M. Máquinas sembradoras de grano gruesso. Santiago: FAO, 1986. 48 p.

EMPRESA BRASILEIRA DE PESQUISA AGROPECUÁRIA. Centro Nacional de Pesquisas de Solos. Manual de métodos de análise do solo. Rio de Janeiro, 1997. 212 p.

EMPRESA BRASILEIRA DE PESQUISA AGROPECUÁRIA. Centro Nacional de Pesquisas de Solos. Sistema Brasileiro de Classificação de Solos. Brasília, 1999. 412 p.

FRANCIS, G.S.; KNIGHT, T.L. Long-term effects of conventional and no-tillage on selected soil properties and crop yelds in Caterbuy, New Zealand. Soil \& Tillage Research, Amsterdam, v.26, n.1, p.193-210, 1993.

FURLANI, C.E.A. Efeito do preparo do solo e do manejo da cobertura de inverno na cultura do feijoeiro (Phaseolus vulgaris L.). 2000. 218 f. Tese (Doutorado em Energia na Agricultura) Faculdade de Ciências Agronômicas, Universidade Estadual Paulista, Botucatu, 2000.

FURLANI, C.E.A.; LOPES, A.; TIMOSSI, P.C. Manejo: trituradores e roçadoras. Cultivar Máquinas, Pelotas, n.18, p.27-9, 2003.

HERMAWAN, B.; CAMERON, K.C. Structural changel in a silt loam under long-term conventional or minimum tillage. Soil \& Tillage Research, Amsterdam, v.26, n.1, p.139-50, 1993.

KLEIN, V.A.; SIOTA, T.A.; ANESI, A.L.; BARBOSA, R. Efeito da velocidade na semeadura direta da soja. Engenharia Agrícola, Jaboticabal, v.22, n.1, p.75-82, 2002.

KLEIN, V.A.; LIBARDI, P.L. ; SILVA, A.P. Resistência mecânica do solo à penetração sob diferentes condições de densidade e teor de água. Engenharia Agrícola, Jaboticabal, v.18, n.2, p.45-54, 1998.

KURACHI, S.A.H.; COSTA, J.A.S.; BERNARDI, J.A.; COELHO, J.L.D.; SILVEIRA, G. Avaliação tecnologica de semeadoras e/ ou adubadoras: tratamento de dados de ensaios e regularidade de distribuição longitudinal de sementes. Bragantia, Campinas, v.48, n.2, p.249-62, 1989.

MIELKE, L.N.; DORAN, J.W.; RICHARDS, K.A. Physical environment the surface of plowed and no-tillage soils. Soil \& Tillage Research, Amsterdam, v.7, p.355-66, 1986.

NAGAOKA, A.K.; NOMURA, R.H.C. Tratores: semeadura. Cultivar Máquinas, Pelotas, n.18, p.24-6, 2003.

SILVEIRA, P.M.; SILVA, J.G.; STONE, L.F.; ZIMMERMANN, J.P. Efeito do preparo na densidade do solo. Santo Antônio de Goiás: Embrapa, 1999. (Pesquisa em Foco n.23)

STOLF, R.; FERNANDES, J.; FURLANI NETO, V. Penetrômetro de impacto: modelo IAA/ Planalsucar - Stolf. STAB, Piracicaba, v.1, n.3, p.18-23, 1983. 